Article

\title{
Research Progress in the Conservation and Development of China-Nationally Important Agricultural Heritage Systems (China-NIAHS)
}

\author{
Qingwen Min ${ }^{1,2, *}$ and Bitian Zhang ${ }^{1,2}$ \\ 1 Institute of Geographic Sciences and Natural Resources Research, CAS, Beijing 100101, China; \\ zhangbt.16b@igsnrr.ac.cn \\ 2 College of Resources and Environment, University of Chinese Academy of Sciences, College of Resources \\ and Environment, Beijing 100049, China \\ * Correspondence: minqw@igsnrr.ac.cn
}

Received: 30 September 2019; Accepted: 18 December 2019; Published: 23 December 2019

check for updates

\begin{abstract}
To cope with the problem of the global agricultural environment, food security, and the crisis of sustainable agricultural development, the Food and Agriculture Organization (FAO), together with other relevant national organizations and several countries, launched the Globally Important Agricultural Heritage Systems (GIAHS) in 2002. The Qingtian Rice-Fish system was designated as China's first GIAHS and was included in the first batch of GIAHS pilot sites, in 2005. Since then, study of systematic agricultural heritage and its conservation and development has progressed in China. On the basis of a comprehensive collection of relevant studies, the author reviews the main achievements in conservation and development of China-Nationally Important Agricultural Heritage Systems (China-NIAHS) over the past 15 years. At the present stage, the core contents of study on agricultural heritage are focused on two aspects. One is the benefit of exploration with multi-functional development. Another is dynamic conservation with adaptive management. There are many controversies around the concept and connotation of agricultural heritage, which, in turn, promote the understanding of this new type of heritage. The sustainable mechanism within agricultural heritage gives itself value diversity. Study about the value of agricultural heritage highlights the significance of conservation. The development of multi-functional industrials based on its multi-functional value is the pathway for the development of China-NIAHS, including the production of high-quality and characteristic local agricultural products, the development of ecotourism, and the development of cultural industries. To carry out dynamic conservation and adaptive management, the establishment of "five in one" benefit-sharing, multi-stakeholder mechanisms, legally guaranteed incentive mechanisms, government-leading, multi-financing mechanisms, and multi-disciplinary scientific support mechanisms are indispensable. Although China has made great progress in the study of agricultural heritage, it still needs to carry out additional research through heritage resources surveys, regular patterns of system evolution, and sustainable mechanisms, as well as perform more applicable research in framework and mechanism construction and paradigms of dynamic protection. Multidisciplinary comprehensive studies are necessary as well.
\end{abstract}

Keywords: agricultural heritage system; important agricultural heritage system; dynamic conservation; adaptive management; conservation and development; study review

\section{Introduction}

Globalization and urbanization have formed two trajectories in the change of agricultural landscapes, both leading to the degeneration of precious traditional landscapes. More economically 
productive areas have been intensified or urbanized, whereas remote, economically unproductive farm areas are increasingly abandoned or reforested with the creation of nature reserves or parks [1]. Intensive farming has proved to be unsustainable [2], and a true wilderness is an elusive concept, making the effect of wilderness conservation questionable [3]. The dramatic decrease in traditional agricultural landscape diversity has contributed to a related reduction in biodiversity and ecosystem functions [4-6].

Fortunately, during the past 30 years, the heritage values of agricultural landscapes have gradually been recognized [7]. The United Nations Educational, Scientific and Cultural Organization (UNESCO) took the organically evolved continuing agricultural landscapes into the category of World Heritage (http://whc.unesco.org/archive/opguide13-en.pdf). The International Union for Conservation of Nature (IUCN) designated sustainable landscapes or seascapes as a Category V protected area.

The Food and Agriculture Organization of the United Nations (FAO) launched an initiative for the management and conservation of Globally Important Agricultural Heritage Systems (GIAHS) in 2002. The goals of the program were to establish global recognition of unique, traditional agricultural systems and their associated landscapes, biodiversity, knowledge systems and cultures, and to ensure their conservation and sustainable management [8].

According to the definition of FAO (http://www.fao.org/giahs/en/), agricultural heritage system is a kind of sustainable, traditional, and globally important rural cultural landscape. The concept of GIAHS is included in other initiatives, such as the UNESCO Biosphere Reserve and World Heritage designations, which is a rediscovery of the 'sacred landscape' belief system of traditional societies, and is an attempt towards an integrated management strategy to conserve natural resources for sustainable use, with inter-generational equity concerns [9].

China was one of the first countries to actively participate in this initiative. In 2005, the Qingtian Rice-Fish Culture System was designated as the first GIAHS in China through the joint efforts of the Ministry of Agriculture and Rural Affairs of the People's Republic of China (MOA) and the Institute of Geographic Sciences and Natural Resources Research (IGSNRR), raising the curtain of systematic discovery, conservation, development, and inheritance of agricultural heritage systems in China [10,11]. In 2012, MOA announced the designation of China-Nationally Important Agricultural Heritage Systems (China-NIAHS).

In the 15 years since the original GIAHS designation, 91 China-NIAHS have been designated in four separate batches, and 18 China-NIAHS have been designated as 15 GIAHS (the GIAHS Rice Terrace in Southern Mountainous and Hilly areas system consists of four China-NIAHS) [10].

Researchers have addressed the issues surrounding China-NIAHS; they have progressively contributed to the identification and recognition of China-NIAHS sites, explored the function and value of possible sites, suggested institution to support heritage conservation and management, and proposed approaches to ensure site conservation and sustainability. We have reviewed the published research concerning the conservation and sustainable operation of China-NIAHS sites. This paper summarizes the progress that has been made in the initiative and proposes a research program to support the coming phases.

\section{Definition, Characteristics, and Value of China-NIAHS}

\subsection{Definition and Characteristic of China-NIAHS}

Agricultural heritage is a broad concept. It conjoins tangible and intangible cultural heritage with agricultural knowledge and practices. An agricultural heritage system is, in contrast, a relatively narrow notion. China-NIAHS refer to the agricultural systems inherited through generations and formed by long-term coevolution of local people with their environment, being rich in biological diversity, traditional knowledge and technologies, remarkable ecological and cultural landscapes, and containing GIAHS designated by FAO and China-NIAHS designated by MOA. This definition was published by MOA in 2012, drawing from Chinese NIAHS research and scholarship and GIAHS criteria. 
An agricultural heritage system embodies the multiple characteristics of natural heritage, cultural heritage, and intangible cultural heritage, which can be concluded as living, dynamic, adaptive, complex, strategic, multi-functional, sustainable, and endangered $[9,12]$. In effect, there are many overlaps between agricultural heritage systems and protected areas. For example, the Cultural Landscape of Honghe Hani Rice Terraces is identified as a GIAHS, a World Cultural Heritage site, and a national wetland park; Xinhua Ziquejie Terraces is a GIAHS and a World Heritage Irrigation Structure. Globally, about 10 (out of 57 in 2019) GIAHS sites are also World Heritage sites.

\subsection{Multi-Values of China-NIAHS}

Agricultural heritage conservation is intended to preserve agricultural sustainability within an ecosystem and to maintain a traditional society. It is of great importance in addressing some of the major challenges faced by humanity, such as ensuring food security, alleviating poverty, maintaining biodiversity, adapting climate change, and protecting cultural diversity [8].

The benefits of successfully meeting these challenges can be divided into five categories: environmental and ecological benefits, economic and subsistence benefits, social and cultural benefits, scientific and educational benefits, as well as instructive and utility benefits. The ability to exploit the many benefits of an agricultural heritage system provides a premise for the conservation and rational utilization of China-NIAHS.

(1) Environmental and Ecological Benefits.

Environmental and ecological benefits are embodied in two aspects. On one hand, China-NIAHS sites are agriculturally extremely heterogeneous in terms of biodiversity. They provide conditions that encourage genetic variety, which is a strong foundation for sustainable agriculture and thus for a viable local economy [13]. Scientists at Zhejiang University conducted molecular and morphological analyses of carp in the Qingtian Rice-Fish Culture. The fish are genetically very diverse and have formed a unique local population [14].

On the other hand, China-NIAHS could provide various ecosystem services and benefits. There has been much research into traditional farming practices in paddy fields such as the Qingtian Rice-Fish Culture and the Congjiang Dong's Rice-Fish-Duck System, mainly in the form of field experiments. The interactions between plants and animals are key to understanding the ecology of these systems. In a rice-fish system, for example, interspecific interaction can be simplified to the following cycle. Fish feed on flowers and insect pests that fall from the rice into the water. Fish excrement is an organic fertilizer for the rice. The movement of fish loosens the soil, thus increasing oxygen available to rice plant roots, which increases rice growth. Research also indicates that these interactions control pests and diseases of rice plants [15-18], improve soil fertility [19], increase soil microbial activity [20], and change growth traits like root shape and lodging resistance [21]. Rice yield is increased, and the application of chemical fertilizers and pesticides is reduced by up to 30\% [22]. Additionally, the ecological benefits increase as the diversity of field fish increases [23].

Research into rice terraces (another major agricultural heritage system) has focused on water control and regulation (i.e., water conservation due to forest cover and water purification due to gravity irrigation systems) [24-28]. Significant ecological functions in other types of agricultural heritage systems have also been well researched, especially for the representative ones of each type. Examples are the flood regulation service contributed by the high-terrain farmland of the Xinghua duotian agrosystem [29], soil retention service displayed due to ancient mulberry trees of the traditional mulberry system in Xiajin's Ancient Yellow River Course [30], and the carbon sequestration in jasmine and tea plants of Fuzhou jasmine and tea culture system [31].

(2) Economic and Subsistence Benefits.

Adequate environment, plentiful biological resources, and unique regional features of agricultural heritage system sites ensure the nutrition and food safety for local residents and inhabitants, and give 
the landscape an aesthetic appeal [32], all of which are conducive to the development of additional economic activity to increase farmers' incomes [33]. Most agricultural heritage systems are in areas of poverty that lack modern technology, so how to transform resources into income for local inhabitants is an urgent issue. There have been many attempts for this issue, involving academic research and government action, which are discussed in Section 5.

(3) Social and Cultural Benefits.

China-NIAHS contains complex cultural intensions, which are embodied in township regulations, customs, folk culture, and traditional knowledge [13], and are fundamental to creating a balanced social-ecosystem nexus. On one hand, China-NIAHS is important for balancing human needs with natural resources. Culture resources are critical for the stability of agricultural heritage systems because they are a necessary guarantee for the conservation of the natural environment, landscape, and biodiversity. Culture forms bonds and conventions that are borne by individual inhabitants. Studies in Hani terraces show that traditional values are powerful forces to defend external threats and maintaining internal structure. For the external part, traditional culture could keep farmers in their homelands and continue to pursue a pure agricultural household strategy [34]. For the internal part, traditional indigenous knowledge is the secret of ecological function's realization [35,36]. On the other hand, China-NIAHS can also promote harmony between humans. Alternative industries, such as leisure agriculture and eco-tourism in heritage sites could increase the economic development of the countryside, thereby improving the co-development of urban and rural areas and thus promoting social stability [37].

(4) Scientific and Educational Benefits.

As a natural laboratory for scientific research, China-NIAHS sites contain many scientific secrets that await discovery [13]. Landscape is an integrating concept that refers both to a physical reality that originates from the continuous and dynamic interaction of natural processes and human activity, and to immaterial existential values and symbols that the landscape embodies [38]. In that case, China-NIAHS are types of rural cultural landscapes and are typical socio-economic-natural systems, with complicated mechanism concerning ecology, biology, sociology, history, and folklore. Landscape issues are of interest in many disciplines. However, human and natural sciences as well as the arts still need to be integrated into a holistic discipline [39]. Therefore, multidisciplinary research is necessary for holistic research, and the integration of disciplines should be promoted in the actual research process.

(5) Exemplary and Widely Used Value.

China-NIAHS are remarkable examples of rational utilization of natural resources and cultural diversity, providing valuable experiences for sustainable agriculture development, particularly in the fields of environmentally adaptive farming and disaster management, owing to its complex, adaptive characteristic $[40,41]$. For example, the Aohan dryland farming system has demonstrated agricultural breeding and farming practices in arid areas [42]. Hani terraces have provided disaster prevention and mitigation plans for the drought in the mountainous area $[28,43]$. The Xinghua duotian agrosystem showed how to manage soil and water in a low-lying wetland area [29].

\section{Management Mechanism of China-NIAHS}

\subsection{Regulation and Policy Establishment}

Researchers have contributed insights to the development and establishment of regulatory control of China-NIAHS sites. Some researchers take the view that, in addition to complying with international conventions, the establishment of a large local conservation framework is also needed. Such a framework would include determination of the autonomy of local communities, regulation of the conservation of environmental resources, assurance of the protection of the intangible cultural heritage, and put it into local legislation to ensure the effect of conservation. 
Some researchers think that national legislation, which would illuminate heritage standards, heritage ownership, and management systems, is necessary to ensure effective agricultural heritage system conservation [44]. National regulation can incorporate and reference other relevant laws and regulations $[45,46]$. Research we have cited laid a solid foundation for the "Procedures on the Administration of Important Agricultural Heritage Systems" (http:/jiuban.moa.gov.cn/ zwllm/zcfg/nybgz/201509/t20150907_4818823.htm) enacted in 2015, which was the first legislative document governing the management of China-NIAHS. It consists of four parts: application and identification, conservation and management, utilization and development, supervision and inspection. The document provides specific requirements for the implementation of the procedures it contains [10].

Researchers from several disciplines, especially ecology and history, have proposed the criteria and principles that could be used to identify and designate China-NIAHS [47,48]. Their views were integrated by MOA in the announcement of "Criteria for the selection of China-NIAHS" in March 2012 (http://www.moa.gov.cn/nybgb/2012/dsiq/201805/t20180514_6141988.htm). The criteria consist of two parts, basic measures and supplementary measures. There are four categories of basic measures (historical relevance, completeness, sustainability, and endangered situations) and two categories of supplementary measures (demonstration of effects and guarantees). The difference between the criteria for China-NIAHS and GIAHS is in historical relevance. China-NIAHS are required to be either the origin or great innovator of agricultural species or technologies and to have existed for at least 100 years. In this case, although China-NIAHS are potential candidates for GIAHS selection, the criteria of China-NIAHS are even stricter than the GIAHS criteria.

On the basis of the criteria and principle study, researchers methodically developed an agricultural heritage system survey, the results of which, such as "potential agricultural heritage systems list of China", "agricultural heritage system survey report of Beijing city", and "agricultural heritage system survey report of Jiangsu province", have been published. Those agricultural heritage systems, which were realized through survey, are backup resources for the identification of China-NIAHS.

\subsection{Management System}

A China-NIAHS site management system of "government-led, scientific argumentation, multiple-participant, hierarchical management, and classified guidance" has been drafted after years of discussion and exploration. Although the framework has been established, practical management protocols are still being determined, particularly at the local government level. Since the management of agricultural heritage involves many departments, its conservation and development is a problem of the holistic region. Current decentralized management greatly constrains the management of agricultural heritage sites, making it necessary to improve the management system and clarify the rights and responsibilities of all stakeholders [45]. Local governments of heritage sites must incorporate the conservation and development of agricultural heritage into the regular agenda and conduct compatible management with reference to other types of heritage. For example, in the Hani terrace, all affairs concerning the conservation of agricultural heritage, world heritage, and national wetland park is dealt with by one authority, the World Heritage administration of Honghe Hani and Yi Autonomous Prefecture. Efficient and unified management could be easily achieved. Meanwhile, the establishment of benefit-sharing, multi-stakeholder participation and legal-guaranteed incentive mechanisms could gather power from different bodies to oversee and evaluate the management of the site.

\subsection{Monitoring and Evaluation}

Monitoring and evaluation are important aspects of agricultural heritage management. It is necessary to comprehensively evaluate the benefits obtained from an agricultural heritage system. It is also necessary to develop an effective monitoring system that enables the management body to identify and analyze the effects of conservation and development measures [49]. The monitoring and evaluation system of China-NIAHS shall include a monitoring network, a body responsible for observation and inspection, the production of an annual status report, and periodic evaluation of the 
management institution. It is also necessary to ensure that the people responsible for monitoring and evaluating are continuously trained, to carefully select the objects and processes that are monitored, and to ensure the ongoing development of monitoring methods [50].

The joint efforts of MOA and researchers resulted in the implementation of a dynamic monitoring system in 2017. The recommendations for a monitoring network, a body responsible for observation and inspection, production of an annual report, and periodic management evaluation were incorporated into the system. Additionally, a database management system was developed to standardize the data collection and to facilitate the online completion of annual reports [10]. The indicators monitored are for key heritage elements (including biodiversity, culture, technologies, knowledge), management actions, and industry development status. However, statistics on ecology and environment are relatively hard to obtain due to the limitation of capital and equipment, therefore, the monitoring of keystone species and ecological functions remains qualitative.

We urge improvement in the methods of monitoring and evaluation of ecological functions to overcome the shortcomings of qualitative data. Existing monitoring studies are largely based on secondary data; most researchers have been concerned with landscape characteristics and soil nutrients and have used GIS and geo-statistical tools [51,52]. Onsite monitoring studies are rare, the most notable exceptions being long-term observations of soil nutrient and gas fluxes in the Fuzhou Jasmine and Tea Culture System [31,53,54].

Both management actions of China-NIAHS and effectiveness need to be evaluated. As of now (2019), there is no specialist research into either. Consequently, the study of reward and punishment mechanism has not been effectively advanced, which has been used as a guarantee mechanism by UNSECO for years. Nevertheless, studies on the management of China-NIAHS could be used for the design of former part, as well as rstudies about characteristic, value, and sustainable capacity of China-NIAHS $[19,55,56]$. Additionally, the industry development of China-NIAHS sites could serve for the design of the latter part. However, most existing studies use cross-sectional data, and time-series data are rare. Thus, research results have little to offer in terms of supporting the evaluation of the effectiveness of management actions. The limited availability of useful data can also be attributed to the short time period over which monitoring has occurred.

\section{Conservation Mechanism of China-NIAHS}

\subsection{Principles of Conservation}

The original purpose of FAO for the conservation of agricultural heritage was "dynamic conservation and adaptive management" [8]. For China-NIAHS, the principles of conservation are that it should be dynamic, integral, and onsite.

Dynamic conservation means to inherit heritage through sustainable utilization. Agricultural heritage aims to protect a comprehensive lifestyle, production technology, and ecological landscape, which is inseparable from the traditional agricultural activities of the residents in heritage sites [57]. Unlike museum-style static conservation, the conservation of agricultural heritage systems emphasizes that dynamic conservation should act according to changing characteristics and circumstances over time [58]. Dynamic conservation requires that we should pay attention to the benefits of contemporary economic and technological developments and increase the income streams of farmers to maximize employment in heritage communities.

Integral conservation is the protection of both agricultural heritage systems and the environment they depend on. The conservation of an agricultural heritage system is a project that intends to protect the totality of the ecosystem, the economic system, and the cultural system so that it is inheritable [59]. The conservation objects of an agricultural heritage system include not only the material part (e.g., various resources, traditional farming tools, traditional villages, field landscape), but also the intangible components (e.g., traditional knowledge, folk culture, farming technology, and resource management technology). 
There are two aspects to onsite conservation. One is that agricultural heritage sites cannot be transferred in space. The other is that the responsibility of conserving and inheriting agricultural heritage should be entrusted to local farmers [59].

\subsection{Mechanism of Conservation}

Following the principle of conservation, five important conservation mechanisms have been put forward, including function-expanded dynamic conservation, benefit-sharing multi-stakeholder participation, legal-guaranteed incentive, government-leading multi-financing, and multi-disciplinary science support [12]. Function expansion is a summary of the roadmap of dynamic conservation and sustainable development, and it is discussed in detailed in Section 5.

Multistakeholder participation has been found to be extremely valuable and has been widely incorporated in sustainable landscape management [60,61]. It was identified as necessary at the beginning of the GIAHS project [62]. Over the years of trial and adjustment, the multistakeholder participation for the conservation of China-NIAHS has become a very positive force, which could be expressed as Five-in-One: conservation is led by governments, promoted by scientists, driven by enterprises, guaranteed by active participation of communities and farmers, and receives cooperation from social organizations [57].

Benefit-sharing is essential to combine the five into a solid one. The community is the steward and owner of an agricultural heritage system. It participates directly in heritage conservation as well as agricultural production, landscape maintenance, cultural inheritance, and market management. The community should therefore be the main beneficiary of conservation. In practice, however, the benefits, particularly those gained from tourism, are not always received by local farmers. Studies of coordination between interested parties in Hani Rice Terraces show that common interests among government, business, and the local communities are relatively distant, and that the community must be more strongly empowered and have a greater voice in decision making and benefit-sharing [63].

Payment for ecosystem services (PES) is central to the use of legally guaranteed incentives and government-led multisource financing for the conservation of China-NIAHS. Studies have shown that agroecosystem services have an external positive value, but in a general economic accounting framework, the comprehensive benefits of ecological farming practices are usually underestimated. Thus, it is necessary to establish a PES mechanism in agricultural heritage conservation [64]. Research into several agricultural heritage sites has investigated the core issues surrounding the use of PES, which are the assessment of ecological value, determination of ecological payments, payment methods, funding sources, and regulatory measures $[65,66]$. However, due to the limit of financing channels, in which the government cannot afford the payment money, the PES of China-NIAHS remains ethereal.

\section{Development Roadmap for China-NIAHS Sites}

\subsection{Multi-function Agriculture}

The agriculture multi-function refers to not only the basic productive function that provides commodities like foods and fibers, but also the usually ignored ecological, cultural, and social functions. There has been a paradigm shift in agricultural and rural strategies from concern about the profitability of food production to the competitiveness of rural areas [67]. However, internally motivated agricultural heritage conservation would not occur unless full play is given to the inherent versatility of agriculture and in which heritage sites are developed economically [68-70]. Given that, China-NIAHS sites should focus on producing eco-cultural agriculture products and developing cultural leisure industries based on local ecology and cultural resources endowment [71]. Thus, based on agricultural production, a detailed function-expanded dynamic conservation mechanism was proposed, which includes the development of an agricultural product processing industry, food manufacturing industry, biological resources industry, cultural and creative industry, and rural tourism [57]. 
There are clearly obstacles to the economic development of heritage sites: ecological fragility, little infrastructure for commercial development, the small scale of potential businesses, few opportunities for business integration, and insufficient support for labor and capital [72,73]. To solve the problem in industrial development, maximizing advantages of heritage resources and achieving coordinated industrial development, Zhang put forward a theoretical framework, together with the implementation path for industrial integration development of agricultural heritage system sites, and proposed the evaluation method of integration degree as well as the attentions for practice [74].

\subsection{High-Quality and Characteristic Agricultural Products}

High quality and uniqueness are two principal defining factors of products that should be developed by businesses related to agricultural production in China-NIAHS sites, such as agricultural production industry, product processing industry, food manufacturing industry, and biological resources industry in China-NIAHS sites. High-quality agricultural products include organic foods, green foods, pollution-free products, and specialty products [75]. Specialty products include geographical indication and regional public brands regulated by MOA.

The production and marketing of organic foods, green foods, and pollution-free products not only is conducive to the conservation of traditional agricultural technology and agricultural culture, but also contributes to increasing farmers' income and thus promoting local sustainable development. The adequate eco-environment in China-NIAHS sites provides basic support to produce those healthy and pricey products. Although the yield of traditional production styles is usually not high, a study of Hani terraces showed that, if production is scaled up, traditional production methods result in greater benefits than modern production methods [74].

Geographical indication provides a legal guarantee that a product is genuine. In an agricultural heritage system, we need to exploit the culture intension of specific geographical indication products, taking full advantage of historical, emotional, and literary values of traditional agricultural culture to promote the integration of culture and agricultural industry and prolong the industry of agricultural production [76]. When we use regional public brands, we use the scale effect to enhance brand awareness and recognition, which is why we need to create a wild spreading scale of certain China-NIAHS products.

The endpoint of agricultural product development is to build a powerful China-NIAHS specialty brand for each heritage site, including all the high-quality and characteristic agricultural products in such sites, not limited to the most representative products, such as Hani red rice or Qingtian field fish. A benefit-sharing consortium of all stakeholders across the whole region is necessary to maximally exploit the brand; it would include all related businesses and might benefit from electronic commerce. China-NIAHS sites could additionally benefit from using modern media to expand their influence and increase the value added to agricultural products by cultural packaging [77].

\subsection{Tourism Industry}

The planned development of eco-tourism in heritage sites can improve the quality of life of the inhabitants while maintaining the traditional landscape to a certain extent [78,79]. The characteristics and conservation principle of China-NIAHS render its tourism resource with multiple attributes, such as wide distribution, high vulnerability, sensitivity, participation, and compounds [80]. To make a feasible layout of tourism development for China-NIAHS sites, comprehensive evaluation for tourism planning from multiple perspectives has been conducted, such as potential tourism resources [81], the spatiotemporal suitability of tourism development [82], community potential for tourism development [83], and multi-functionality [84]. Furthermore, scholars have proposed a variety of frameworks for sustainable tourism development. Some scholars have classified the China-NIAHS according to the types of tourism resources and put forward pertinent paths for each kind $[80,85]$. Others have cut in from the objectives and principles of conservation, like multi-level objectives (constituted of economic, environment, culture, society, policy) [86] and community-based co-management $[87,88]$, 
proposing tourism development models that are based on meeting these objectives as a prerequisite to the development of tourism.

The development of eco-tourism in agricultural heritage system sites has become a common trend around China. Tourism increases the enthusiasm of the inhabitants of a China-NIAHS site for protecting the site, increases employment in the sites, maintains the economy, and increases social stability [89]. It also helps community residents to deepen their understanding of the heritage system [90]. Although it is necessary to pay attention to balance the relationship between conservation and tourism development [91], empirical investigations show that tourism may trigger environmental and social issues, for instance, environmental pollution, inequitable allocation of benefits [92], increased tension in neighborly relationships, as well as deterioration in public security and social morality [93]. Meanwhile, although the income level of inhabitants in some heritage sites has indeed increased due to the development of eco-tourism [94], the income from ecological agriculture and eco-tourism in many heritage sites still cannot compare with the incomed earned from migration or land transfer [95]. As a result, the transformation of farmers' livelihood strategies at the expense of traditional farming practices and partial sacrifices of traditional agricultural landscapes is widespread [96], and these changes and their adverse effects are threatening the sustainability of heritage systems. There remains much to do to achieve sustainable tourism at China-NIAHS sites, both theoretically and practically speaking.

\subsection{Cultural Industry}

Cultural diversity in agricultural heritage systems is important in that it provides for the transmission of traditional knowledge and the commercialization of a variety of cultural activities such as education, art, and leisure. The premise of cultural industry development is the inheritance and conservation of culture. Thus, it is necessary to establish an incentive mechanism for cultural conservation, increase policy support, and strengthen the construction of the inheritance team [97]. There are three pathways for the development of cultural industry in China-NIAHS.

First, exploit the functions of cultural and leisure, carrying out cultural tourism in heritage sites using traditional folk activities, attracting tourists to attend ceremonies, or play for special agricultural activities, such as the Kam Grand Choirs during slack season in Congjiang and the feast during the new year festival of Hani nationality in the Hani terraces. However, traditional communities are being weakened and twisted by internet exposure and migration trends $[88,98,99]$. Some profit-driven commercialization models ignore the significance and seasonality of traditional folk activities, rendering uncommon activities into daily performing routines. In that case, we must balance the relationship between tradition and innovation to halt the adverse effects of commercialization on the activities and to strengthen control over tourism investors and entrepreneurs to prevent over-commercialization, to respect local customs, and to prevent local inhabitants from losing their identity [100].

The second pathway is to develop value-added cultural products. This can be done by grafting regional culture, geography, and history, which display the rich cultural associations of agricultural products, onto agricultural products through different types of trademark or branding (e.g., scientific, historical, humanistic, regional, or cultural attachment).

Finally, environmental education and interpretation have long been regarded as a powerful weapon for the conservation and sustainable development of protected areas [101]. It is of great significance for the intergenerational inheritance of China-NIAHS and for innovation and development in publishing and education industry as well. Scholars are committed to compiling and publishing popular science books for China-NIAHS, and more than 40 China-NIAHS sites have published their popular science books. Environmental education may have a longer-term influence on personal behavior if it is received at a young age [102]; therefore, directing marketing efforts to target young generations may have a better effect. To this end, some heritage sites have created courses or incorporated the contents of China-NIAHS into teaching materials and examinations. Furthermore, 
six GIAHS sites have cooperated with researchers and artists to design children's picture storybooks, which were published in 2018.

\section{Future Work}

Research in China-NIAHS has made remarkable progress. Empirical observations and policy implications drawn from research support the effectiveness of conservation work by China-NIAHS in promoting economic development, cultural inheritance, and ecological conservation in heritage sites. A multidisciplinary research cadre has been formed, and a new and active discipline has developed, contributing to the research into agricultural heritage systems and their conservation and exploitation. Future work should focus on the following areas.

(1) A comprehensive survey and benefit assessment of agricultural heritage system resources should be brought forward. The agricultural heritage system is a new heritage concept that combines an intertwined natural and cultural inheritance with a separate intangible cultural inheritance; it is also a traditional agricultural production system linking farm, farmer, farm employment, and rural revitalization. An integrated science-based plan is needed that, when implemented, would provide targets and measures that sustainably balance economic development with conservation for China-NIAHS sites. Future work should focus on conducting comprehensive surveys of agricultural heritage systems, analyzing their functions and the benefits they provide, elucidating the urgency of conservation, and exploring the potential for exploitation and economic development.

(2) Conduct in-depth research on the systematic evolution characteristics and the sustainable maintenance mechanism of China-NIAHS. Those could help to reveal the dynamic and changing regulations of agricultural heritage systems and provide a reference for the modern ecological recycling of agriculture and rural revitalization.

(3) More research is required into the organizational structures of the bodies that oversee the conservation and management of China-NIAHS because they are not powerful enough. Research into adaptive management is inadequate to date. Management at the national level needs to be improved. It is necessary to research the methodologies of benefit sharing, creating incentives, financing, and system evaluation. This research should provide the government with direction for continuously improving its management and a method of quantifying the effectiveness of financial support for the development of China-NIAHS sites.

(4) The conservation of China-NIAHS is an emerging concept which cannot simply be applied to the conservation measurements of natural and cultural heritage. It is necessary to explore the paradigm of dynamic conservation according to local conditions and refine the conservation and development modes applicable to different natural ecological conditions, different social and economic levels, and different regional cultural characteristics.

(5) Literature reviews show studies on China-NIAHS mainly concentrate on the discipline of ecology, resource science, and agronomy [103], and is relatively weak in the fields of folk culture, economy, and management. Thus, future work should attract experts from relevant disciplines to carry out comprehensive research and provide scientific and technological support for the effective conservation and sustainable utilization in China-NIAHS sites, paying attention to strengthening the regional development characteristics of agricultural heritage system conservation.

Author Contributions: Q.M. conceived the framework of research. and revised the paper. B.Z. wrote and revised the paper. All authors have read and agreed to the published version of the manuscript.

Funding: This study is supported by the Foundation of Discovery and Conservation of China's Important Agricultural Heritage System (grant no. Y9L90370AJ).

Conflicts of Interest: The authors declare no conflict of interest. 


\section{References}

1. Beilin, R.; Lindborg, R.; Stenseke, M.; Pereira, H.M.; Llausàs, A.; Slätmo, E.; Cerqueira, Y.; Navarro, L.; Rodrigues, P.; Reichelt, N.; et al. Analysing how drivers of agricultural land abandonment affect biodiversity and cultural landscapes using case studies from Scandinavia, Iberia and Oceania. Land Use Policy 2014, 36, 60-72. [CrossRef]

2. Tilman, D.; Fargione, J.; Wolff, B.; D'antonio, C.; Dobson, A.; Howarth, R.; Schindler, D.; Schlesinger, W.H.; Simberloff, D.; Swackhamer, D. Forecasting Agriculturally Driven Global Environmental Change. Science 2001, 292, 281-284. [CrossRef] [PubMed]

3. Phillips, A. The nature of cultural landscapes-A nature conservation perspective. Landsc. Res. 1998, 23, 21-38. [CrossRef]

4. Agnoletti, M. The degradation of traditional landscape in a mountain area of Tuscany during the 19th and 20th centuries: Implications for biodiversity and sustainable management. For. Ecol. Manag. 2007, 249, 5-17. [CrossRef]

5. Pereira, H.M.; Leadley, P.W.; Proenca, V.; Alkemade, R.; Scharlemann, J.P.W.; Fernandez-Manjarres, J.F.; Araujo, M.B.; Balvanera, P.; Biggs, R.; Cheung, W.W.L.; et al. Scenarios for Global Biodiversity in the 21st Century. Science 2010, 330, 1496-1501. [CrossRef]

6. Taylor, K.; Lennon, J. Cultural landscapes: A bridge between culture and nature? Int. J. Herit. Stud. 2011, 17, 537-554. [CrossRef]

7. Mitchell, N.J.; Barrett, B. Heritage Values and Agricultural Landscapes: Towards a New Synthesis. Landsc. Res. 2015, 40, 701-716. [CrossRef]

8. Cruz, M.J.D.; Koohafkan, P. GloballyImportant AgriculturalHeritage Systems: ASharedVision of Agricultural, Ecological andTraditional Societal Sustainability. Res. Sci. 2009, 31, 905-913.

9. Ramakrishnan, P.S. Globally Important Ingenious Agricultural Heritage Systems (GIAHS): An Eco-Cultural Landscape Perspective; GIAHS Background Document; FAO: Rome, Italy, 2004.

10. Jiao, W.; Min, Q. Reviewing the Progress in the Identification, Conservation and Management of China-Nationally Important Agricultural Heritage Systems (China-NIAHS). Sustainability 2017, 9, 1698. [CrossRef]

11. Min, Q.; Sun, Y.; Sun, Y. GIAHS Project and Its Implementation in China. J. Resour. Ecol. 2010, 1, 94-96.

12. Min, Q.; Zhang, Y.; Jiao, W.; Sun, X. Responding to common questions on the conservation of agricultural heritage systems in China. J. Geogr. Sci. 2016, 26, 969-982. [CrossRef]

13. Min, Q.; He, L.; Sun, Y.; Zhang, D.; Yuan, Z.; Xu, Y.T.; Bai, Y. On the value, conservation and sustainable development of GIAHS pilot sites in China. Chin. J. Eco-Agric. 2012, 20, 668-673. (In Chinese) [CrossRef]

14. Ren, W.; Hu, L.; Guo, L.; Zhang, J.; Tang, L.; Zhang, E.; Zhang, J.; Luo, S.; Tang, J.; Chen, X. Preservation of the genetic diversity of a local common carp in the agricultural heritage rice-fish system. Proc. Natl. Acad. Sci. USA 2018, 115, E546-E554. [CrossRef] [PubMed]

15. Liu, M.; Bai, Y.; Cao, Z.; Xu, Y. Ecological control of rice pest/disease and application in Southwest China. Chin. J. Eco-Agric. 2012, 20, 734-738. (In Chinese) [CrossRef]

16. Zhang, D.; Cheng, S.; Yang, H.; He, L.; Jiao, W.; Liu, S.; Min, Q. Ecological Control Effects on Pest, Pathogen and Weed of Multiple Species Coexistence in Paddy Fields in Traditional Agricultural Regions. Res. Sci. 2011, 33, 1032-1037. (In Chinese)

17. Xie, J.; Hu, L.; Tang, J.; Wu, X.; Li, N.; Yuan, Y.; Yang, H.; Zhang, J.; Luo, S.; Chen, X. Ecological mechanisms underlying the sustainability of the agricultural heritage rice-fish coculture system. Proc. Natl. Acad. Sci. USA 2011, 108, E1381-E1387. [CrossRef]

18. Tang, J.; Xie, J.; Chen, X.; Yu, L. Can rice genetic diversity reduce Echinochloa crus-galli infestation? Weed Res. 2009, 49, 47-54. [CrossRef]

19. Lu, J.; Li, X. Review of rice-fish-farming systems in China-One of the Globally Important Ingenious Agricultural Heritage Systems (GIAHS). Aquaculture 2006, 260, 106-113. [CrossRef]

20. Zhang, J.; Xu, R.; Quan, G.; Xu, H.; Qin, Z. Effects of Integrated Rice-Duck Farming on Soil Microbial Quantity and Functional Diversity. Res. Sci. 2009, 31, 56-62. (In Chinese)

21. Huang, Z.; Zhang, J.; Liang, K.; Quan, G.; Zhao, B. Mechanical stimulation of duck on rice phyto-morphology in rice-duck farming system. Chin. J. Eco-Agric. 2012, 20, 717-722. (In Chinese) [CrossRef] 
22. Xie, J.; Wu, X.; Tang, J.; Zhang, J.; Chen, X. Chemical fertilizer reduction and soil fertility maintenance in rice-fish coculture system. Front. Agric. China 2010, 4, 422-429. [CrossRef]

23. Ren, W.; Hu, L.; Zhang, J.; Sun, C.; Tang, J.; Yuan, Y.; Chen, X. Can positive interactions between cultivated species help to sustain modern agriculture? Front. Ecol. Environ. 2014, 12, 507-514. [CrossRef]

24. Jiao, Y.; Cheng, G.; Xiao, D. A study on the cultural landscape of Hani's terrace and its protection. Geogr. Res. 2002, 21, 733-741. (In Chinese)

25. Adachi, S. Agricultural technologies of terraced rice cultivation in the Ailao Mountains, Yunnan, China. Asian Afr. Area Stud. 2007, 6, 173-196.

26. Feng, J.; Shi, S.; He, S. Hani terrace ecosystem in Yunnan Province. J. Cent. Univ. Nat. 2008, 17, $146-153$. (In Chinese)

27. Bai, Y.; Min, Q.; Liu, M.; Yuan, Z.; Xu, Y.; Cao, Z.; Li, J. Resilience of the Hani Rice Terraces System to Extreme Drought. J. Food Agric. Environ. 2013, 11, 2376-2382.

28. Li, J.; Jiao, W.; Min, Q.; Li, W. Effects of Traditional Ecological Knowledge on the Drought-Resistant Mechanisms of the Hani Rice Terraces System. J. Res. Ecol. 2016, 7, 211-217.

29. Bai, Y.; Sun, X.; Tian, M.; Anthony, M.F. Typical Water-Land Utilization GIAHS in Low-Lying Areas: The Xinghua Duotian Agrosystem Example in China. J. Resour. Ecol. 2014, 5, 320-327.

30. Sun, X.; Wang, B.; Liu, M.; Liu, W. The Ecosystem Service Function of Shandong Xiajin Yellow River Ancient Mulberry Trees System and Its Effect on Regional Ecosystem. J. Resour. Ecol. 2016, 7, 223-230.

31. Wang, W.; Min, Q.; Sardans, J.; Wang, C.; Asensio, D.; Bartrons, M.; Peñuelas, J. Organic Cultivation of Jasmine and Tea Increases Carbon Sequestration by Changing Plant and Soil Stoichiometry. Agron. J. 2016, 108, 1636-1648. [CrossRef]

32. Cao, Y.; Wu, Y.; Zhang, Y.; Tian, J. Landscape pattern and sustainability of a 1300-year-old agricultural landscape in subtropical mountain areas, Southwestern China. Int. J. Sustain. Dev. World Ecol. 2013, 20, 349-357. [CrossRef]

33. Zhao, F.; Nie, R.; Zhang, J.E. Greenway Implementation Influence on Agricultural Heritage Sites (AHS): The Case of Liantang Village of Zengcheng District, Guangzhou City, China. Sustainability 2018, 10, 434. [CrossRef]

34. Zhang, Y.; Min, Q.; Zhang, C.; He, L.; Zhang, S.; Yang, L.; Tian, M.; Xiong, Y. Traditional culture as an important power for maintaining agricultural landscapes in cultural heritage sites: A case study of the Hani terraces. J. Cult. Herit. 2017, 25, 170-179. [CrossRef]

35. Wang, J.; Xi, C.; Pi, S. Study on indigenous knowledge system for management of ecosystem diversity in Mengsong Hani Community, Xishuangbanna. Chin. J. Ecol. 2000, 19, 36-40.

36. Jiao, Y.; Li, X.; Liang, L.; Takeuchi, K.; Okuro, T.; Zhang, D.; Sun, L. Indigenous ecological knowledge and natural resource management in the cultural landscape of China's Hani Terraces. Ecol. Res. 2011, 27, 247-263. [CrossRef]

37. Sun, Y.; Min, Q.; He, L. Agricultural Heritage Systems: A Bridge between Urban and Rural Development. J. Resour. Ecol. 2016, 7, 187-196.

38. Antrop, M. Sustainable landscapes: Contradiction, fiction or utopia? Landsc. Urban Plan. 2006, 75, $187-197$. [CrossRef]

39. Palang, H.; Helmfrid, S.; Antrop, M.; Alumäe, H. Rural Landscapes: Past processes and future strategies. Landsc. Urban Plan. 2005, 70, 3-8. [CrossRef]

40. Tony, F.; Min, Q. Understanding Agricultural Heritage Sites as Complex Adaptive Systems: The Challenge of Complexity. J. Resour. Ecol. 2013, 4, 195-201.

41. Fuller, A.M.; Min, Q.; Jiao, W.; Bai, Y. Globally important agricultural heritage systems (giahs) of China: The challenge of complexity in research. Ecosyst. Health Sustain. 2017, 1, 1-10. [CrossRef]

42. Sun, X.; Min, Q.; Bai, Y.; Anthony, M.F. Analyzing Environmental Stress Counter-Measures in Agricultural Heritage Sites in China. J. Resour. Ecol. 2014, 5, 328-334.

43. Sun, Y.; Zhou, H.; Zhang, L.; Min, Q.; Yin, W. Adapting to droughts in Yuanyang Terrace of SW China: Insight from disaster risk reduction. Mitig. Adapt. Strateg. Glob. Chang. 2012, 18, 759-771. [CrossRef]

44. Zhang, B. Legislative conception of agricultural cultural heritage protection in China. West. Law Rev. 2013, 5, 34-40. (In Chinese)

45. Li, M.; Wang, S.M. Survey and Practice of Agro-cultural Heritage Protection in Jiangsu. Agric. Hist. China 2011, 30, 128-136. (In Chinese) 
46. Li, G. Discussion on Legal Protection for Legacy of Agricultural Culture. J. Beijing Univ. Agric. 2007, 22, 46-49.

47. Min, Q. Explanations and Enlightenments of the GIAHS's Criteria. Resour. Sci. 2010, 32, $1022-1025$. (In Chinese)

48. Yuan, L.; Gu, J. Study on the Selection Criteria of Agro-cultural Heritage. J. China Agric. Univ. (Soc. Sci. Ed.) 2012, 29, 16-19. (In Chinese)

49. Yang, B.; He, L.; Min, Q.W. Monitoring and Evaluation of Agricultural Heritage and its Framework Design Based on International Experiences. J. China Agric. Univ. (Soc. Sci. Ed.) 2014, 31, 127-132. (In Chinese)

50. Min, Q.; Zhao, G.; Jiao, W. Progress of World Heritage Monitoring and Evaluation and enlightenments to China's Agriculture Heritage Systems Management. World Agric. 2015, 11, 97-100. (In Chinese)

51. Li, J.; Min, Q.; Li, W.; Bai, Y.; Bijaya, G.C.; Yuan, Z. Spatial Variability Analysis of Soil Nutrients Based on GIS and Geostatistics: A Case Study of Yisa Township, Yunnan, China. J. Resour. Ecol. 2014, 5, 348-355.

52. Xu, Y.; Min, Q.; Yuan, Z.; Bai, Y.; Sun, Y.; Li, J.; Cao, Z. Identifying Landscape Pattern Metrics for the Hani Terrace in Yunnan, China. J. Resour. Ecol. 2013, 4, 212-219.

53. Wang, C.; Li, X.; Min, Q.; Wang, W.; Sardans, J.; Zeng, C.; Tong, C.; Peñuelas, J. Responses of greenhouse-gas emissions to land-use change from rice to jasmine production in subtropical China. Atmos. Environ. 2019, 201, 391-401. [CrossRef]

54. Tian, M.; Min, Q.; Lun, F.; Yuan, Z.; Fuller, A.; Yang, L.; Zhang, Y.; Zhou, J. Evaluation of Tourism Water Capacity in Agricultural Heritage Sites. Sustainability 2015, 7, 15548-15569. [CrossRef]

55. Jiao, W.; Min, Q.; Cheng, S.; Zhang, D.; Sun, Y. The Emergy-based Ecological Footprint (EEF) of Traditional Agricultural Areas in China: A Case Study of Congjiang County, Guizhou Province. J. Resour. Ecol. 2011, 2, $56-65$.

56. Jiao, W.; Min, Q.; Cheng, S.; Zhang, D.; Sun, Y.H. Ecological footprint analysis on the traditional rice-fish agricultural area: A case study of Qingtian County, Zhejiang Province, China. Ecol. Econ. 2009, 5, 365-374.

57. Min, Q. Remarks on the application for world cultural heritage of the Hani Paddy-Rice Terraces. Acad. Explor. 2009, 3, 12-23. (In Chinese)

58. Xia, S.; Ma, Q.; Zhang, J.; Xu, S. Renascence of agricultural heritage tourism from the ecological perspective: A case study of longxian village in qingtian country. J. Landsc. Res. 2013, 5, 37-40.

59. Yuan, L.; Gu, J.; Xu, X. Three Theoretical Issues in the Disciplinary Construction of Agricultural Heritage. J. Nanjing Agric. Univ. (Soc. Sci. Ed.) 2012, 12, 126-133. (In Chinese)

60. Vos, W.; Meekes, H. Trends in European cultural landscape development: Perspectives for a sustainable future. Landsc. Urban Plan. 1999, 46, 3-14. [CrossRef]

61. Stenseke, M. Local participation in cultural landscape maintenance: Lessons from Sweden. Land Use Policy 2009, 26, 214-223. [CrossRef]

62. Lee, Y.J.; Lee, D.Y. An Analysis on Collaborative Relationships of Stakeholders of KIAHS. J. Korean Soc. Rural Plan. 2019, 25, 11-20.

63. Shi, S.; Sun, Y. Research on Interests Coordination in the Tourism Development of the World Cultural Heritage Site from the Perspective of Social Network Analysis: Taking Hani Rice Terraces in Yunnan as an Example. Tour. Trib. 2016, 31, 52-64.

64. Li, W.; Liu, M.; Min, Q. China's Ecological Agriculture Progress and Perspectives. J. Resour. Ecol. 2011, 2, 1-7.

65. Liu, M.; Xiong, Y.; Bai, Y.; Yang, L.; Min, Q. Ecological compensation standard for the Hani Rice Terrace System: An eco-functional-oriented improvement. Acta Ecol. Sin. 2017, 37, 2447-2454. (In Chinese)

66. Liu, M.; Xiong, Y.; Yuan, Z.; Min, Q.; Sun, Y.; Anthony, M.F. Standards of ecological compensation for traditional eco-agriculture: Taking rice-fish system in Hani terrace as an example. J. Mt. Sci. 2014, 11, 1049-1059. [CrossRef]

67. Park, J.; Kim, S.; Lee, E. Adoption and Future Tasks of Nationally Important Agricultural Heritage System for Agricultural and Rural Resources Conservation. J. Korean Soc. Rural Plan. 2013, 19, 161-175. [CrossRef]

68. Min, Q.; Zhang, D.; He, L.; Sun, Y. Agri-cultural Heritage Research and Conservation Practices in China:Progresses and Perspectives. Resour. Sci. 2011, 33, 1018-1024. (In Chinese)

69. Liu, P.; Gao, Q.; Xu, W. An Analysis on the Relationship between Agricultural Heritage Conservation and Socio-Economic Development. Anc. Mordern Agric. 2008, 4, 89-98. (In Chinese) 
70. Agnoletti, M.; Cargnello, G.; Gardin, L.; Santoro, A.; Bazzoffi, P.; Sansone, L.; Pezza, L.; Belfiore, N. Traditional landscape and rural development: Comparative study in three terraced areas in northern, central and southern Italy to evaluate the efficacy of GAEC standard 4.4 of cross compliance. Ital. J. Agron. 2011, 6, 16. [CrossRef]

71. Li, W.; Liu, M.; Min, Q. Agricultural heritage conservation: New opportunity for developing eco-agriculture. Chin. J. Eco-Agric. 2012, 20, 663-667. [CrossRef]

72. Zhang, C.; Shen, G. Multifunction of Agricultural Heritage and Its Industrial Development and Industrial Convergence Approaches. China Agric. Univ. J. (Soc. Sci. Ed.) 2016, 33, 127-135.

73. Zhang, Y.; Min, Q. A review of conservation of rice terraces as agricultural heritage systems. Chin. J. Eco-Agric. 2016, 24, 460-469.

74. Zhang, Y.; Li, X.; Min, Q. How to balance the relationship between conservation of Important Agricultural Heritage Systems (IAHS) and socio-economic development? A theoretical framework of sustainable industrial integration development. J. Clean. Prod. 2018, 204, 553-563. [CrossRef]

75. He, L.; Min, Q.; Zhang, D.; Jiao, W.; Yang, H.; Liu, S. Study on Agricultural Development Mode in Traditional Agricultural Areas:A Case Study of Congjiang County of Guizhou Province. Resour. Sci. 2009, 31, $956-961$. (In Chinese)

76. Wu, B.; Sun, Q. Research on agricultural culture and protection of agricultural cultural heritage - an interview with professor Wu Bingan. J. China Agric. Univ. (Soc. Sci. Ed.) 2012, 29, 28-44. (In Chinese)

77. Yuan, L. The Chinese Agricultural Heritage Protection and Utilization of Cross-industry Participation into the Era of "List". J. China Agric. Univ. (Soc. Sci. Ed.) 2014, 31, 133-136. (In Chinese)

78. Su, M.; Wall, G. Chinese Research on World Heritage Tourism. Asia Pac. J. Tour. Res. 2011, 16, 75-88. [CrossRef]

79. Kausar, D.R.; Nishikawa, Y. Heritage Tourism in Rural Areas: Challenges for Improving Socio-economic Impacts. Asia Pac. J. Tour. Res. 2010, 15, 195-213. [CrossRef]

80. Sun, Y.; Min, Q.; Cheng, S.; Zhong, L.; Qi, X. Study on the Tourism Resource Characteristics of Agricultural Heritage. Tour. Trib. 2010, 25, 57-62. (In Chinese)

81. Sun, Y.; Cheng, S.; Zhong, L.; MIN, Q. Assessment on Tourism Resources Potential for Agricultural Heritage sites: A Case Study on Qingtian Country in Zhejiang Province. Res. Sci. 2010, 32, 1026-1034.

82. Sun, Y.; Min, Q.; Cheng, S. The Temporal and Spatial SuitabilityAssessment in the TourismResources Development of AgriculturalHeritage System. Res. Sci. 2009, 31, 942-949.

83. Sun, Y.; Min, Q. The community potential for tourism development in agricultural heritage sites: A case study of Qingtian County. Geogr. Res. 2011, 30, 1341-1350.

84. He, L.; Min, Q. The Role of Multi-functionality of Agriculture in Sustainable Tourism Development in Globally Important Agricultural Heritage Systems (GIAHS) Sites in China. J. Resour. Ecol. 2013, 4, 250-257.

85. Min, Q.; Sun, Y.; Cheng, S.; Wang, X. Primary study on the features and development of GIANS's tourism resources. Econ. Geogr. 2007, 5, 856-859. (In Chinese)

86. Tian, M.; Min, Q.; Jiao, W.; Yuan, Z.; Fuller, A.M.; Yang, L.; Zhang, Y.; Zhou, J.; Cheng, B. Agricultural Heritage Systems Tourism: Definition, characteristics and development framework. J. Mt. Sci. 2016, 13, 440-454. [CrossRef]

87. Sun, Y.; Wang, J.; Liu, M. Community Perspective to Agricultural Heritage Conservation and Tourism Development. J. Resour. Ecol. 2013, 4, 258-266.

88. Gu, H.; Jiao, Y.; Liang, L. Strengthening the socio-ecological resilience of forest-dependent communities: The case of the Hani Rice Terraces in Yunnan, China. For. Policy Econ. 2012, 22, 53-59. [CrossRef]

89. Sun, Y.; Jansen-Verbeke, M.; Min, Q.; Cheng, S. Tourism Potential of Agricultural Heritage Systems. Tour. Geogr. 2011, 13, 112-128. [CrossRef]

90. Sun, Y.; Zhou, H.; Wall, G.; Wei, Y. Cognition of disaster risk in a tourism community: An agricultural heritage system perspective. J. Sustain. Tour. 2016, 25, 536-553. [CrossRef]

91. Wang, L.; Cheng, S.; Zhong, L.; Mu, S.; Dhruba, B.G.C.; Ren, G. Rural tourism development in China: Principles, models and the future. J. Mt. Sci. 2013, 10, 116-129. [CrossRef]

92. Tang, X.; Min, Q.; Wu, Z. An Investigation of Residents' Perception on Tourism in Agro-Cultural He ritage Community: A Case Study on Ping'an Village of Guilin City, Guangxi. Res. Sci. 2010, 32, 1035-1041.

93. Tang, X.; Yu, X.; Zhang, D. A Study of Agri-Cultural Heritage Tourism Impacts Based on Residents' Perception: Taking the Longji Terrace Site in Guilin as an Example. J. Resour. Ecol. 2013, 4, 267-274. 
94. Zhang, Y.; He, L.; Li, X.; Zhang, C.; Qian, C.; Li, J.; Zhang, A. Why are the Longii Terraces in Southwest China maintained well? A conservation mechanism for agricultural landscapes based on agricultural multi-functions developed by multi-stakeholders. Land Use Policy 2019, 85, 42-51. [CrossRef]

95. Su, M.; Sun, Y.; Min, Q.; Jiao, W. A Community Livelihood Approach to Agricultural Heritage System Conservation and Tourism Development: Xuanhua Grape Garden Urban Agricultural Heritage Site, Hebei Province of China. Sustainability 2018, 10, 361. [CrossRef]

96. Yang, L.; Liu, M.; Min, Q.; Li, W. Specialization or diversification? The situation and transition of households' livelihood in agricultural heritage systems. Int. J. Agric. Sustain. 2018, 16, 455-471. [CrossRef]

97. Hu, L.; Tang, J.; Zhang, J.; Ren, W.; Guo, L.; Halwart, M.; Li, K.; Zhu, W.; Qian, Y.; Wu, M.; et al. Development of rice-fish system: Today and tomorrow. Chin. J. Eco-Agric. 2015, 23, 268-275. (In Chinese)

98. Yuan, Z.; Lun, F.; He, L.; Cao, Z.; Min, Q.; Bai, Y.; Liu, M.; Cheng, S.; Li, W.; Fuller, A. Exploring the State of Retention of Traditional Ecological Knowledge (TEK) in a Hani Rice Terrace Village, Southwest China. Sustainability 2014, 6, 4497-4513. [CrossRef]

99. Yuan, J.; Wu, Q.; Liu, J. Understanding indigenous knowledge in sustainable management of natural resources in China. For. Policy Econ. 2012, 22, 47-52.

100. Tang, X.; Min, Q.; He, L. Measurement and regulation of socio-cultural impact of tourism in agro-cultural heritage site-A cause study of Longji Ping'anzhai Terrace in Guilin, Guangxi. Chin. J. Eco-Agric. 2012, 20, 710-716. [CrossRef]

101. Hungerford, H.R.; Volk, T.L. Changing Learner Behavior Through Environmental Education. J. Environ. Educ. 1990, 21, 8-21. [CrossRef]

102. Liefländer, A.K.; Fröhlich, G.; Bogner, F.X.; Schultz, P.W. Promoting connectedness with nature through environmental education. Environ. Educ. Res. 2013, 19, 370-384. [CrossRef]

103. Zhang, Y.; He, L.; Min, Q. Research progress of agricultural heritage in China based on literature statistics. Res. Sci. 2017, 39, 175-187. (In Chinese)

(C) 2019 by the authors. Licensee MDPI, Basel, Switzerland. This article is an open access article distributed under the terms and conditions of the Creative Commons Attribution (CC BY) license (http://creativecommons.org/licenses/by/4.0/). 